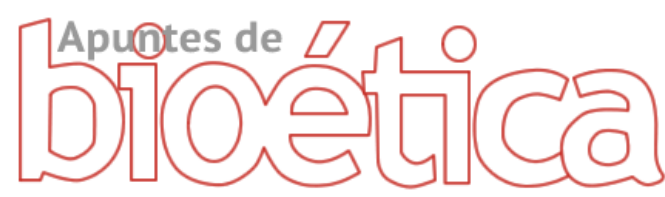

https://doi.org/10.35383/apuntes.v1i1.190

\title{
Fundamentos lusnaturalistas para analizar la STC N 09332-2006-PA/TC en lo referente a las nuevas estructuras familiares
}

\author{
Ana Guadalupe Bayona Salcedo ${ }^{1}$
}

\section{INFORMACIÓN DEL ARTÍCULO}

Historia del artículo:

Recibido el 27 de setiembre de 2018

Aceptado el 20 de noviembre de 2018

\section{Palabras claves:}

Familia

Nuevas estructuras familiares Tribunal

Constitucional

\section{RESUMEN}

El presente artículo tiene como objetivo presentar unos fundamentos lusnaturalistas que permitan analizar la STC No 09332-2006-PA/TC en lo referente a las nuevas estructuras familiares, reconocidas por el Tribunal Constitucional Peruano. Sobre el particular es preciso señalar que ciertamente la sociedad peruana experimenta en los últimos años un cambio significativo en cuanto a la institución familiar se refiere, como consecuencia del proceso de adaptación al tiempo presente, motivo por el cual han surgido diversas estructuras similares a la familia, "con una dinámica diferente". (Fundamento 9 STCP), que conviven con la familia en el entramado social. El advenimiento de estas estructuras familiares ha exigido del Estado un grado de protección. A través de la mencionada Sentencia el Tribunal Constitucional Peruano (STCP) ha reconocido "que se hayan generado familias con estructuras distintas a la tradicional, como son las surgidas de las uniones de hecho, las monoparentales (...) y las familias reconstituidas" (Fundamento 7 STCP) o ensambladas; ampliando así el concepto constitucional de familia que, como contempla el artículo 4 de la Constitucional peruana que establece que es una institución natural y fundamental de la sociedad. De esta manera el Tribunal Constitucional ha equiparado estas estructuras con la familia, dando cabida a un concepto de institución familiar pluralizada, apartándose del modelo garantizado en la Constitución Peruana. Consideramos que esta asimilación generará un debilitando de la institución familiar.

${ }^{1}$ Abogada, Maestro en Persona, Matrimonio y Familia de la Universidad Santo Toribio de Mogrovejo. Email agubasal@yahoo.es ORCID: https://orcid.org/0000-0001. $\underline{8754-0832}$ 


\section{Natural law foundations to analyze STC $\mathrm{N}^{\circ}$ 09332-2006-PATC regarding new family structures}

\section{ABSTRACT}

Keywords:

Family

New family structures

Constitutional
The purpose of this communication some foundation natural law in order to analyze the STC No. 09332-2006-PA / TC regarding new family structures recognized by the Constitutional Court. This regard should be noted that certainly Peruvian society experienced in recent years a significant change in the family institution is concerned, as a result of the adaptation process to the present time, why have been a number of similar structures to the family "with a different dynamic," (basis 9) living with the family in the social fabric. The advent of these family structures has required the state a degree of protection. Through the aforementioned judgment, the Constitutional Court has recognized "families that were generated with different structures than the traditional, such as those arising from de facto unions, single (...) and stepfamilies" (basis 7) or assembled; thus broadening the constitutional concept of family as referred to in Article 4 "is a natural and fundamental institution of society" allowing for a concept of pluralized family institution, away from the model guaranteed in the Constitution. We believe that this assimilation will generate a weakening of the family institution.

\section{Introducción}

Durante años la familia en el Perú ha sido identificada con el modelo nuclear, basado en la concepción naturalista y el matrimonio heterosexual, según reconoce nuestra Constitución Política del Perú (CPP) en su artículo 4. Este modelo es el constitucionalmente garantizado. La familia atraviesa hoy un proceso de adaptación a la época de posmodernidad. Por este motivo, junto a ella, y como fruto de diversos factores (Burgos, 2004) han surgido estructuras familiares flexibles y diversas. Frente a esta realidad familiar, el Tribunal Constitucional Peruano (TCP) a través de la Sentencia No 09332-2006-PA/TC, señaló erróneamente que hay "un cambio en la estructura de la familia tradicional nuclear que ha generado familias con estructuras distintas a la tradicional, como son las surgidas de las uniones de hecho, las monoparentales o las (...) reconstituidas". (STCP Fundamento 7). Esto constituye un error, puesto que la estructura de la familia como instituto natural no ha cambiado ni cambiará. Lo que sí es cierto es la existencia de estas nuevas estructuras familiares fruto del debilitamiento de la institución familiar en Perú, a tal punto que el concepto de familia como institución natural, fundada en el matrimonio, está siendo vaciado de contenido a través de la hipervaloración de la autonomía de la voluntad (Vasallo y Muga, 2012) y de otros aires de doctrinas que buscarían redefinir la institución familiar. También es propio indicar que incluso a niveles académicos se viene propagando un modelo constitucional alejado 
del primigenio. Se hace, pues, necesario revalorar la familia rescatando su carácter constitucional original. Creemos que la respuesta se encuentra en el lusnaturalismo, por lo que surge la siguiente interrogante a investigar: ¿Cuáles son los fundamentos lusnaturalistas para analizar la STC 09332-2006PATTC en lo referente a las nuevas formas familiares?

Para dar respuesta a esta interrogante, establecemos como objetivo de este artículo presentar los fundamentos lusnaturalistas que permitan analizar la STC No 09332-2006-PATC, en lo referente a las nuevas estructuras familiares, reconocidas por el Tribunal Constitucional; con lo cual se permitirá apreciar y fortalecer el concepto de familia como institución natural, basada en el matrimonio, la misma que merece el reconocimiento y protección de la comunidad y el Estado, no exclusivo ni excluyente, frente a las nuevas estructuras familiares.

\section{Metodología}

La investigación es de tipo cualitativa, de corte humanista, descriptiva e interpretativa, haciendo énfasis en la importancia de la familia como institución natural, desde una visión lusnaturalista, frente a las nuevas estructuras familiares. A través del abordaje metodológico se ha acopiado la información necesaria visitando la biblioteca y adquiriendo libros en físico y virtuales, así como copias de otros. Las técnicas utilizadas se han centrado en la clasificación y organización de las fuentes, con anotaciones y sumillas en las mismas, directamente o a través de notas adhesivas y marcadores, así como el resumen. Los instrumentos han sido fundamentalmente la observación documental y la organización física y virtual del material recolectado. Los sujetos de la investigación están constituidos por la familia, las nuevas estructuras familiares y el Estado.

\section{Resultados, análisis y discusión}

\section{Cuestiones Previas}

Creemos convenientes dar algunos pinceladas respecto de algunos temas relvantes que consideramos importantes para el tema a investigar. Así tenemos:

\section{La familia}

Existen diversas posturas sobre el concepto de familia, desde la más limitativa, nuclear tradicional (STC 09332-2006-PA/TC, fundamento 6), hasta la más flexible, según la cual estaría integrada por todos los que cohabitan bajo el mismo techo. (Canales, 2008). Por nuestra parte presentamos una aproximación de lo que consideramos es la familia, según las finalidades que se suelen reconocer en ella:

Desde los primeros tiempos la familia cumple tres misiones y persigue tres finalidades: una natural, la de vincular al hombre y a la mujer y conservar el género humano; otra económica, consistente en la obtención de alimentos para todos los familiares y techo para los que convivan; una tercera, moral $y$ espiritual, es decir, el mutuo socorro de los familiares, la comunidad de vida entre ellos, y el cuidado y educación de la prole. (La Cruz, como se citó en Corral, 2005, p.29).

La familia es, pues, el pilar fundamental de la comunidad humana, unidad básica fundada en el matrimonio, en la que los cónyuges, hombre y mujer, abiertos a la generación, inauguran juntos un proyecto de vida, para ayudarse y auxiliarse mutuamente, y establecen unas relaciones que les son propias. Frente a 
este sólido concepto de familia, se abre camino otro que la considera como un término "desactualizado", que debe modificarse porque la familia ha evolucionado hacia nuevos tipos de familia, por lo que sería más acertado hablar de "las familias" (Vía, 2008) en lugar del singular familia (Varsi, 2012, p. 23). Consideremos qué efecto provocaría el pasar a un nuevo concepto plural y diversificado. Faltaría la identidad. Si no tiene identidad y se presenta como una especie de plasma que puede adoptar las más diversas formas, entonces todo puede ser familia. El problema es que si cualquier relación humana puede ser calificada como familiar, entonces ninguna lo es específicamente. Como señala Haaland como se citó en Corral: Si todo es familia, nada es familia (2014, p. 58).

\section{Modelo constitucional de familia en el Perú}

Nuestra CPP, siguiendo la corriente contemporánea de introducir en las Constituciones normas relativas a la familia, (Plácido, 2001, p. 22) como fruto de una preocupación social por el buen funcionamiento de las mismas, (Corral, 2005, p. 48) establece el modelo constitucional de familia, como instituto natural, junto con el matrimonio. Nuestro ordenamiento reconoce que la familia es una sociedad natural y por lo tanto antecede a la sociedad civil, (Vasallo y Muga, 2012) en consecuencia no es una creación ni del Derecho ni de la ley, que solo la regulan, sino que es obra de la naturaleza humana (Cornejo, 1999); no creada por la voluntad del hombre, sino que le viene exigida desde sus orígenes, de ahí que todo lo que le atañe (propiedades, fines, derechos, deberes, etc.) son de ley y derecho naturales. (Hervada, 1998, p.133). Familia y matrimonio guardan inmediata relación, la familia natural es protegida y el matrimonio promovido.

En el marco nacional, la Ley de Política Nacional de población establece que "el Estado fortalece la familia como unidad básica de la sociedad promoviendo y ayudando su estabilidad y constitución formal" (Decreto Legislativo $\mathrm{N}^{\circ}$ 346, art. 2); el artículo 233 del Código Civil de 1984 establece que el fin de regular la familia es fortalecerla. En este mismo sentido se expresa la decimosexta política de Estado del fortalecimiento de la familia, del Acuerdo Nacional. En el marco internacional también es reconocida como elemento natural y fundamental de la sociedad que tiene derecho a ser protegida por la sociedad y el Estado (Declaración de los Derechos Humanos, art. 16,3); se reconoce el derecho a contraer matrimonio y fundar una familia, (art. 1 y 16) etc. Los Estados, y en particular el nuestro, la protegen porque reconocen en ella unos atributos que le son muy propios, y que pasan de la familia al propio Estado: lugar y origen de la vida, perpetuidad de la sociedad; primera comunidad interpersonal, intersexual, intergeneracional; lugar de las relaciones más humanas y esenciales: amor, maternidad, paternidad, filiación; centro del afecto; en ella, finalmente, se desarrollan diversas funciones sociales, económicas, educativas, de ayuda, etc. (Burgos, 2013).

Aunque el modelo de familia constitucionalmente garantizado es el originado en el matrimonio, sin embargo, por analogía, se llama familia tanto a la surgida en un hogar de hecho ${ }^{2}$, como a otras NEF que, en su esencia y por los lazos que las unen, son similares a la familia como institución natural. El concepto

\footnotetext{
2 “La unión estable de un varón y una mujer, libres de impedimento matrimonial, que forman un hogar de hecho, da lugar a una comunidad de bienes sujeta al régimen de la sociedad de gananciales en cuanto sea aplicable". Artículo 5, Constitución Política del Perú.
} 
jurídico de familia queda delimitado como aquella comunidad de un hombre y una mujer, basada en el matrimonio. (Flores, 2014, p. 14).

Concluiremos, manifestando que disentimos con quienes argumentan que la familia como institución natural, responde a la tradición, a la cultura, o a una época de la historia que va llegando a su fin. Ella responde más bien a la naturaleza propia de la persona, como veremos más adelante.

\section{Las Nuevas Estructuras Familares en el Perú en relación a la Sentencia del Tribunal Constitucional Peruano $\mathrm{N}^{\circ}$ 09332-2006- PATC}

Las Nuevas Estructuras Familiares son aquellas estructuras sociales de tipo familiar muy similares a la familia "natural", a las que les falta algún elemento determinante para alcanzar su plenitud y equilibrio.

A través de la STC 09332-2006-PATC se reconocieron las nuevas estructuras familiares, "las familias surgidas de las uniones de hecho, las monoparentales y las que en doctrina se han denominado familias reconstituidas". (Fundamento 8). El Tribunal Constitucional se ocupó del reclamo de don Reynaldo Armando Shols Pérez, quien tras solicitar al Centro Naval del Perú le otorgara a su hijastra un carné familiar igual que al hijo nacido dentro de la nueva estructura familiar, fue rechazada su petición. ${ }^{3}$ El Tribunal Constitucional le "otorga

\footnotetext{
${ }^{3}$ Los hijastros habían sido tratados como hijos, hasta que mediante un acuerdo directivo de 2002 aprobaron otorgar a los hijastros pase de invitado especial válido por un año, renovable hasta los 25 años. La génesis del proceso se inicia cuando en primera instancia fue rechazada la demanda interpuesta, declarándose infundada debido a que no se tenía regulada la situación de los hijastros y por lo tanto al demandante no le asistía ningún derecho para reclamar un carné para la menor. Shols Pérez apela la sentencia, siendo que el Tribunal en segunda instancia la declaró improcedente, dado que el demandante no poseía legitimidad para actuar por no ser ni el padre biológico de la menor ni su representante legal.
}

tutela jurisdiccional efectiva al actor y en estricto respeto del deber constitucional de protección de la familia, declara fundada la demanda de amparo" (Calderón, 2014, p. 75) ordenando la emisión del carné a su hijastra bajo la equiparación con una hija biológica (Vega, 2008). El Poder Judicial (2008) afirmó que nuestra legislación no puede ser ajena al contexto social por lo que se hace necesaria y urgente la protección a todas las familias, aun cuando no tengan como base el matrimonio, ello independientemente de si tal situación sea positiva o no para la convivencia y el desarrollo social. Consideremos cómo el accionar de Shols provocó que el Tribunal Constitucional se pronuncie respecto de las nuevas estructuras familiares y en concreto sobre las reconstituidas (Gaceta Constitucional, marzo 2008) y a través de ello, participara en la construcción de la defensa de derechos paterno-filiales provocados por nuevas situaciones sociales, como lo es el divorcio en la actualidad. Vemos cómo el eje de discusión dio un giro: del derecho lesionado del actor se centrará en lo que el Tribunal Constitucional deduce que proviene de la CPP, la invocación del derecho a la constitución de una familia y al reconocimiento y respeto a la nueva estructura familiar . (Silverino, p.3).

La STC 09332-2006-PA/TC presenta la disociación de elementos antes inevitablemente ligados: el matrimonio desligado de la sexualidad, la sexualidad de la procreación, la filiación, etc. Como consecuencia de estas situaciones los operadores del Derecho buscan soluciones no muchas veces acordes con el bien de la persona y de su naturaleza. (Silverino, año, p. 9). El Tribunal Constitucional incorporó al ordenamiento jurídico la familia ensamblada, concepto que no se encontraba recogido en ninguna norma ( Vega, 2008), y la definió a partir de sus propias características. (Sentencia 09332-2006-PA/TC. Fundamento 8). 


\section{Fundamentos lusnaturalistas para analizar la STC 09332-2006-PATC en lo referente a las nuevas estructuras familiares}

He aquí algunas consideraciones que nos permitirán establecer el carácter originario de la familia, desde el lusnaturalismo de Javier Hervada.

\subsection{Protección de la persona humana y dignidad}

A la familia se la pretende erosionar en sus bases más profundas tratando de confiscar el carácter natural que le es propio. Frente a ello J. Hervada afirma que en cada persona humana existe una real estructura fundamental llamada naturaleza humana, que conforma a cada hombre (Hervada, 2008, p. 479), y la familia está conformada por esta persona humana que, precisamente se edifica en el núcleo familiar. En ese ambiente natural se desarrolla. Cuando la STC 09332-2006-PA/TC equipara a la familia con las nuevas estructuras familiares, está trastocando el ámbito natural donde la persona ha de ser y desarrollarse, toda vez que constituyen "estructuras frágiles de materializar". (Fundamento 14 STCP).

A la dignidad de la persona humana también se le pretende vaciar de contenido (Hervada, 2008) J. Hervada puntualiza que la persona es una sustancia de naturaleza racional por lo tanto su dignidad es una eminencia de ser -la persona es ser perfectísimo- objetiva, inherente a la ontología de la persona e independiente de estimaciones subjetivas; $y$ consiste en aquella perfección del ser que comporta el orden del deber-ser (debitud y exigibilidad, en el plano personal, moral y jurídico). La dignidad de la persona es propia de todo hombre $y$ se constituye en criterio normativo. Un detalle relevante: "como la dignidad tiene su raíz en la naturaleza -sin la naturaleza no hay dignidad- los derechos y deberes radican en la naturaleza humana y constituyen, por tanto, el derecho natural". (2008, p. 486). Atentar contra la familia también constituye un atentado contra esa misma dignidad, porque se le privaría a la persona de un derecho natural que le es propio; siendo así que la dignidad es el valor esencial de los Derechos Humanos, de esta forma si la STC 09332-2006-PA/TC atenta contra la institución familiar, también está vulnerando la dignidad de la persona.

\subsection{La familia protectora de la persona y dignidad}

De lo expuesto en la consideración precedente se concluye que la familia es la que salvaguarda la auténtica concepción de persona y por lo tanto su dignidad. Con esta afirmación no se pretende marginar a otras estructuras familiares. Lo que viene sucediendo es que, por un lado, el individualismo hoy dominante, considera y nos presenta al hombre como un ser biológico-cultural, cuya naturaleza no es otra que su libertad, y que en aras de esa libertad escoge lo que desea, con tal de satisfacer sus gustos y necesidades; y por otro, se propugna la repersonalización de la familia que difiere de la concepción como institución natural. (Varsi, 2012, p.45).

\subsection{El matrimonio como institución natural}

Según recomienda J. Hervada (2000), para comprender la familia es necesario penetrar en 
su esencia, en relación con la misma naturaleza del ser humano (p.104). Varón y mujer se relacionan de acuerdo a las exigencias de comportamiento y trato que dimanan de la naturaleza misma del hombre, virilidadfeminidad, estructuras naturales de la persona humana (1998, p.133). De estas estructuras emana una regla natural de su mutua relación, llamada matrimonio (Corral, 1980, p. 109). La fuerza de la familia como institución natural radica en el amor conyugal (Hervada, 2000, p. 56). De ahí que el matrimonio viene a ser una necesidad exigida por la naturaleza. No es un invento de hombres, ni es una expresión cultural o religiosa. Existe por naturaleza, responde a una ordenación mutua, en función de unas necesidades y finalidades de la especie. De lo que se colige que una de las aspiraciones mayores del hombre y de la mujer es ser fecundo, la mayoría se inclina por un proyecto de vida compartido a través de una relación estable y duradera por lo que, cuando no lo alcanza siente frustración. En la STC 093322006-PA/TC no se hace lo propio, porque aunque sí se habla del matrimonio en los fundamentos 6 (ligado a la familia nuclear), 8 (forma de instituir las estructuras ensambladas) 19 (indicando que no agota el modo de fundar la familia) y por último, el fundamento 21 , en el que se aprecia que ambos cónyuges acreditaban con su partida de matrimonio (el segundo de cada uno de ellos) que constituían un nuevo núcleo familiar. Lo propio del matrimonio es uno con una y esto para toda la vida, aspecto que no suele estar presente en las nuevas estructuras familiares.

\subsection{El matrimonio como unión jurídica}

La noción de matrimonio que nos presenta J. Hervada establece que es una unión jurídica, plena y total, de varón y mujer (virilidad - feminidad), que comporta una comunidad indivisible de vida, cuya finalidad es la generación y educación de los hijos y la ayuda mutua. Si se presenta al matrimonio como una unión jurídica es para dejar claro que no es una unión de hecho ni tampoco constituye una simple legalización, sino más bien un vínculo jurídico. Mediante la entrega recíproca entre el varón y la mujer existe un vínculo jurídico, por el cual, siendo dos, forman una unidad en sus cuerpos (relación jurídica que integra feminidad y virilidad) y en sus almas (por el compromiso contraído), (Hervada, 1998) relación jurídica en cuya virtud son verdaderamente marido y mujer. (Hervada, 2000, p. 95). De ahí que, la distinción entre ciertas formas de concubinato $y$ el matrimonio reside en haber contraído matrimonio, en haberse vinculado los cónyuges mutuamente, mediante el nacimiento del vínculo matrimonial. (Hervada, 1998) Con respecto a las nuevas estructuras familiares reconocidas en la STC 09332-2006-PA/TC, queda clara la diferencia entre ciertas formas de concubinato y la familia matrimonial. Es cierto que en las familias ensambladas puede aparecer el vínculo matrimonial, pero no con las características plenas que se han señalado líneas arriba, sobre todo en cuanto a la comunidad indivisible de vida. $Y$ he aquí la fuerza de la familia matrimonial y por lo tanto la debilidad de las nuevas estructuras familiares.

\subsection{La familia como institución natural}

Considerar a la familia como institución natural es un cometido realmente relevante en este estudio por cuanto la CPP de 1993 reconoce a la familia como institución natural y por consiguiente esa es la postura que pretendemos fortalecer. La familia no es el resultado de un ensayo o pruebas más o menos afortunadas (Ugarte como se citó en Corral, 
2002; no es invención del hombre, le viene exigida por la naturaleza. Si los gobiernos han protegido $y$ protegen a la familia $y$ al matrimonio de hombre y mujer es, precisamente, para perpetuar la especie y para la estabilización de la sociedad. Familia y matrimonio constituyen dos realidades que se funden. J. Hervada nos dice que: el primer núcleo social (hombre y mujer), la primera y más básica comunión, sociedad o comunidad humana y natural es la familia y el matrimonio". (Escrivá, 2008, p. 414). Para J. Hervada toda esta realidad familiar se funda en el matrimonio que une indisolublemente al varón y a la mujer en una caro, integrándolos, por ley natural, en una comunidad de vida, para que en ella puedan perfeccionarse mutuamente, engendrar hijos, recibirlos amorosamente y educarlos. (Escrivá, 2008 , p. 174). En la STC 09332-2006-PA/TC, en la que confusamente se la declara casi como obsoleta, si bien cierto no se la desaparece de plano, sí se la debilita equiparándola con las nuevas estructuras familiares.

\subsection{La familia como bien de la sociedad}

Por esa inclinación connatural a la maternidad y paternidad, el deber de recibir a los hijos obedece a la ordenación esencial de la unidad en la naturaleza. Pero ello no se agota allí, de ahí que el fin del matrimonio sea el hijo educado. Los padres, por su estructura natural, se ordenan para proporcionar a la sociedad hijos formados. Por lo que corresponderá a ambos la formación integral de sus hijos, (Hervada, 2000, p. 742) hijos que mañana serán buenos ciudadanos, dado que, por sus características, la familia desarrolla importantes servicios a la sociedad. Porque en la familia tenemos hijos mientras que en la sociedad, ciudadanos (Varsi, 2012, p. 49). En la STC 09332-2006-PATC, también se expresa este servicio que los padres brindan educando a sus hijos; el TC manifiesta una verdadera preocupación especialmente por el hijo afín, buscando su mejor integración y el bienestar de los integrantes del nuevo núcleo familiar. Por otra parte, la familia como institución natural es considerada no solo universal, sino también, la más óptima para nuestra sociedad y para sus miembros. (Arroyo, 2002). En este sentido también las nuevas estructuras familiares reconocidas en la STC 09332-2006-PA/TC deberán procurarlas.

\section{Conclusiones}

Resulta imprescindible considerar la relación entre familia y naturaleza del ser humano. De esta forma podremos comprender la grandeza de esta institución en toda su profundidad y valorar los grandes aportes que brinda a nuestra sociedad, especialmente en el servicio a las nuevas generaciones de hijos-ciudadanos, dándole cohesión, preservando y transmitiendo nuestros valores, tradición y cultura nacional.

El artículo 4 de la CPP obliga a proteger un modelo concreto de familia, con unas características propias, protección que se encuentra garantizada en los documentos internacionales. Entendemos que en el caso, de la STC 09332-2006-PATC, el Tribunal Constitucional del Perú como supremo intérprete de la Constitución, al tratar de superar el vacío de la ley, habría incurrido en un exceso al equiparar la familia y las nuevas estructuras familiares debido a la labor compleja por procurar protección a las nuevas estructuras familiares.

Respecto del modelo de familia ensamblada así como de las otras nuevas estructuras familiares reconocidas por la STC 09332-2006-PATC, consideramos que, dado este reconocimiento, se 
les debe otorgar un sustento jurídico apropiado, según la naturaleza de cada una. El legislador deberá tener la pericia suficiente para no vulnerar otros derechos constitucionales evitando así su colisión. El Tribunal Constitucional debe velar porque se garanticen los derechos y bienes constitucionalmente protegidos.

La familia se eleva en la sociedad sobre cualquier otra estructura social, o de cualquier otra índole, por su carácter natural que es inherente a la persona humana. El lusnaturalismo de Javier Hervada, ofrece a la persona y a la familia una luz clara para conocer y aceptar su propia identidad y naturaleza, y para reconocer la titularidad de sus propios derechos fundamentales,así como descubrir el fundamento donde se cimenta la realidad de la unión inescindible entre el matrimonio y la familia.

\section{Bibliografía}

Arroyo, A. (2002). Las Familia monoparentales en España. ¿Una desviación u otra forma de organización social? (Memoria para optar el grado de Doctor). Universidad complutense de Madrid, España. Recuperado de http://biblioteca.ucm.es/tesis/cps/ucmt25716.pdf

Bellardinelli, S. (2013). La familia como recurso insustituible de una sociedad abierta y plural Estudios sobre educación, Vol 25, 85-94. Recuperado de https://www.unav.edu/publicaciones/revis tas/index.php/estudios-sobreeducacion/article/viewFile/1882/1752
Burgos, J.M. (2004). Diagnóstico sobre la familia, Madrid, España: Ediciones Palabra.

Burgos, J.M. (2013). Antropología: una guía para la existencia, Madrid, España: Ediciones Palabra.

Calderón, J. (2014). La familia ensamblada en el Perú. Lima, Perú: Adrus Editores.

Canales, C. (2008). Ensamblando paso a paso a "los míos", a "los tuyos" y a "los nuestros". Reconocimiento de las familias reconstituidas por el TC peruano. Gaceta Constitucional. Tomo 06.

Castro, O. M. La constitucionalización del derecho de familia. UNIFE. Recuperado de www.unife.edu.pe/derecho.

Cornejo, H. (1999). Derecho familiar peruano, Lima, Gaceta jurídica, 1999.

Corral, H. (2005). Derecho y derechos de la familia. Lima, Perú: Editora jurídica Grijley.

Corral, H. (2014). Cien años de la revista de Derecho privado 1913 - 2013. Del Derecho de familia a un Derecho de las familias. Madrid, España: Editorial REUS.

Escrivá, I. (2008). Relectura de la obra científica de Javier Hervada. Pamplona: Gráficas Egúzquiza.

Fernández, M. (2013). Manual de Derecho de familia. Lima, Perú: Fondo editorial de la Pontificia Universidad Católica del Perú.

Flores, T.I. (2014). La protección estatal de la familia como institución jurídica natural. (Tesis para optar el título de abogado). Universidad Católica Santo Toribio de 
Mogrovejo, Chiclayo. Recuperado de: http://tesis.usat.edu.pe.

Hervada, J. (1998) Cuatro lecciones de derecho natural. Navarra, España: Ediciones Universidad de Navarra.

Hervada, J. (2000). Una Caro. Escritos sobre el matrimonio. Pamplona: Ediciones Universidad de Navarra.

Hervada, J. (2008). Lecciones propedéuticas de Filosofía del Derecho, Navarra, España: Ediciones Universidad de Navarra.

Hervada, J. (1980). La identidad del matrimonio. Revista Chilena de Derecho, v. VII, p. 109. Citado por CORRAL TALCIANI, Hernán. Derechos y derechos de la familia..., $p$. 47.

Plácido, A. (2001). Manual de Derecho de familia. Lima, Gaceta jurídica.

Plácido, A. (2014). El modelo de familia garantizado en la Constitución de 1993. En El nuevo rostro del Derecho de Familia. Comentarios a la nueva Ley 30007 sobre los Derechos Sucesorios en las Uniones de Hecho, Lima, Perú: Motivensa.

Poder Judicial. (2008). Los Principios constitucionales del Derecho de Familia. Recuperado de www.pj.gob.pe.

Silverino, P. Apuntes de la sentencia del Tribunal $\begin{array}{lcr}\text { Constitucional } & \text { sobre } & \text { familias } \\ \text { ensambladas. } & \text { Recuperado } & \text { de }\end{array}$ www.academia.edu.

Varsi, E. (2012). Tratado de Derecho de Familia. Gaceta Jurídica, Lima, Perú.
Vasallo, K. y Muga, R. (2012). Nuevos Derechos y exigencias para el Derecho de Familia en el Perú. (Tesis para lograr el título de Abogado), Universidad Católica Santo Toribio de Mogrovejo, Chiclayo, Perú. Recuperada de http://tesis.usat.edu.pe.

Vega, Y. (2009). Las nuevas fronteras del Derecho de familia. Familias de hecho, ensambladas y homosexuales, Lima, Perú: Motivensa.

Vega, Y. (abril-junio 2008). La ampliación del concepto de familia por obra del Tribunal Constitucional. A propósito de la incorporación de la familia ensamblada y de la concesión de mayores derechos a la familia de hecho. Gaceta del Tribunal Constitucional $N^{\circ}$ 10. Recuperada de www.pj.gob.pe.

VÍA, J. Algunas reflexiones sobre la familia actual. Recuperado de www.psicologia/articulos/2008. Universid ad de La Habana, 2008.

Ley de política nacional de población. Decreto Legislativo $\quad \mathrm{N}^{\circ} \quad 346$, artículo 2. http://www.mimp.gob.pe/webs/mimp/sis pod/ley_politica_nacional_de_poblacion. pdf

Organización de las Naciones Unidas (ONU). Declaración Universal de los Derechos Humanos. Recuperado de http://www.un.org/es/documents/udhr/in dex_print.shtml.

Organización de los Estados Americanos (OEA). Declaración americana de los Derechos y Deberes del hombre. Recuperado de 
http://www.oas.org/es/cidh/mandato/Basi cos/declaracion.asp.

STC 09332-2006-PATC del 30 de noviembre de 2007. Expediente $\mathrm{N}^{\circ}$ 09322-2006-PA/TC http://www.tc.gob.pe/jurisprudencia/2008/0933 2-2006-AA.htmIS
Jurisprudencia Relevante Comentada. (Marzo 2008) STC. 09332-2006-PATC Gaceta constitucional $\mathrm{N}^{\circ} 3$. 